УДК 556.556.2:551.326.85

МОДЕЛИРОВАНИЕ ТЕЧЕНИЙ В ОЗЕРЕ, ПОКРЫТОМ ЛЬДОМ

Зверев И.С., Здоровеннова Г.Э., Богданов С.Р., Волков С.Ю., Гавриленко Г.Г., Ефремова Т.В., Пальшин Н.И., Здоровеннов Р.Э., Голосов С.Д., Тержевик А.Ю. Институт водных проблем Севера КарНЦ РАН, ФИЦ «Карельский научный изентр РАН», Петрозаводск, Карелия, е-тail: iliazverev@mail.ru

Приведены результаты тестовых численных расчетов течений в малом бореальном озере в зимний период с использованием 3D-модели гидротермодинамики внутреннего моря (МГВМ), адаптированной для случая малого пресноводного озера. В качестве объекта исследования было выбрано небольшое мезотрофное озеро Вендюрское, расположенное в южной части Карелии. Сеточная область была разработана по данным подробной эхолокационной съемки. Количество расчетных уровней - 10. Размер ячеек по вертикали составлял 0,5-3,5 м, по горизонтали - 80×80 м. Для задания граничных условий на поверхности водоема использовались данные реанализа, воспроизводящие среднемноголетние климатические условия в районе исследований. В качестве граничного условия на дне был добавлен поток тепла между донными отложениями и водной массой озера. Модель адекватно воспроизвела годовой ход температуры воды на разных горизонтах водной толщи, даты наступления и окончания ледостава, его продолжительность, динамику нарастания и таяния ледового покрова. В результате численных расчетов установлено, что вскоре после установления льда формируется циклонический круговорот, охватывающий почти полностью центральную глубоководную котловину озера. Этот круговорот устойчив и существует в течение большей части зимы. Скорости течений в этом круговороте достигают 10-15 мм/с в начальный период ледостава, постепенно снижаясь до $0,2-0,5$ мм/с к концу зимы. Сравнение результатов расчетов скоростей течений на МГВМ с данными прямых измерений течений в озере в течение зимы показало хорошее соответствие.

Ключевые слова: бореальное озеро, период ледостава, 3D модель, течения, потоки тепла

\title{
MODELING OF CURRENTS IN AN ICE-COVERED LAKE
}

\section{Zverev I.S., Zdorovennova G.E., Bogdanov S.R., Volkov S.Yu., Gavrilenko G.G., Efremova T.V., Palshin N.I., Zdorovennov R.E., Golosov S.D., Terzhevik A.Yu. Northern Water Problems Institute Karelian Research Centre Russian Academy of Sciences, Petrozavodsk,Karelia,e-mail: iliazverev@mail.ru}

The results of test numerical calculations of currents in a small boreal lake in the winter period are presented using the 3D model of the hydrothermodynamics of the inland sea (MHIS) adapted for the case of a small freshwater lake. A small mesotrophic lake Vendyurskoe, located in the southern part of Karelia, was chosen as the object of study. The grid area was developed according to the detailed echolocation survey. The number of calculated levels was 10 . The vertical size of the cells was $0.5-1.0 \mathrm{~m}$, horizontal $-80 \times 80 \mathrm{~m}$. To set the boundary conditions on the surface of the reservoir, data from the re-analysis were used, reproducing the average long-term climatic conditions in the study area. As a boundary condition at the water-bottom boundary, the heat flux between sediments and water body was included into the model code. The model adequately reproduced the annual course of water temperature at different depths of the water column, the dates of the beginning and end of the freeze-up, its duration, and the dynamics of the growth and melting of the ice cover. As a result of numerical calculations, it was established that the cyclonic circulation, which covers almost completely the central deep-water basin of the lake, is formed shortly after freeze-up. This circulation is stable and exists for most of the winter. The velocities of currents in the circulation reach $10-15 \mathrm{~mm} / \mathrm{s}$ in the initial period of the ice season, gradually decreasing to $0.2-0.5 \mathrm{~mm} / \mathrm{s}$ by the end of winter. Comparison of the results of calculations of current velocities on MHIS with data from direct measurements of currents in the lake during the winter showed good agreement.

Keywords: boreal lake, ice-covered period, 3D-model, currents, heat flux

Термодинамика мелководных озер умеренной зоны играет важнейшую роль в функционировании их экосистем. Температура и скорости течений определяют интенсивность биохимических процессов в водной толще и придонных слоях водоемов. В частности, температура водной толщи и режим перемешивания оказывают определяющее влияние на развитие придонной аноксии [1], на перераспределение клеток водорослей, биогенов, газов по водной толще [2]. Интенсивность динамических процессов может оказывать заметное влияние на жизненные циклы гидробионтов, создавая «благоприятные» условия для видов с разными предпочтениями по динамическому режиму [3].
Таким образом, очевидна актуальность изучения процессов переноса и перемешивания (годовой цикл) в водной толще мелководных озер и выявления их роли в функционировании озерных экосистем.

Слабая изученность зимнего динамического режима водоемов суши связана, с одной стороны, с тем, что скорости течений в период ледостава в малопроточных озерах малы [4], с другой - со сложностью и высокой стоимостью проведения прямых измерений течений в этот период. Скорости подледных течений редко превышают 1-10 мм/с [5], поэтому для их измерений требуются современные приборы с высоким разрешением, что заметно ограничивает возможности постановки натурных 
экспериментов. В этой ситуации численное моделирование заметно расширяет возможности изучения гидротермодинамических процессов в водоемах, покрытых льдом [6].

Цель исследования: оценить возможность применения метода трехмерного численного моделирования для расчета термогидродинамических (ТГД) процессов в небольшом озере в годовом цикле и, особенно в период ледостава.

\section{Материалы и методы исследования}

Трехмерная математическая модель гидротермодинамики внутреннего моря (МГВМ), разработанная в Институте вычислительной математики РАН (ИВМ РАН) и в Институте океанологии им. П.П. Ширшова РАН (ИО РАН) [7] и успешно адаптированная в Институте озероведения РАН (ИнОз РАН) для случая пресноводного озера [8], использовалась для воспроизведения циркуляции в небольшом мелководном озере в зимний период.

В модели для описания циркуляции водной массы и термического режима в бассейне произвольной геометрии используются трехмерные уравнения термогидродинамики. Поверхность раздела воздух - вода свободная, воспроизводятся пространственная изменчивость топографии поверхности и изменчивость среднего уровня водоема. Взаимодействие атмосферы и водной массы описывается через потоки импульса, тепла и влаги. При возникновении условий, благоприятных для формирования льда, включается модель льда, описывающая термодинамические процессы (изменение температуры, нарастание, таяние) во льду и динамические процессы (движение, торошение и т.д.). При этом потоки свойств через границу атмосфера - вода заменяются потоками через границы атмосфера - лед и лед - вода. В модели явным образом описываются потоки воды и ее свойств (минерализация, теплосодержание) через боковые границы (сток и приток рек) и поверхность раздела воздух - вода (испарение, осадки). Кроме того, в модели МГВМ для аппроксимации частных производных использован метод конечных объемов (MКО), основанный на интегральной формулировке законов сохранения массы, импульca, энергии и др. Балансовые соотношения записываются для небольшого контрольного объема; их дискретный аналог получается суммированием по всем граням выделенного объема потоков массы, импульса. Поскольку интегральная формулировка законов сохранения не накладывает ограничений на фор- му контрольного объема, МКО пригоден для дискретизации уравнений гидродинамики как на структурированных, так и на неструктурированных сетках с различной формой ячеек, что решает проблему сложной геометрии расчетной области.

В условиях, как правило, очень сложной геометрии расчетной области для озер Карелии - как глубоких, так и мелководных последнее является неоспоримым и решающим преимуществом для выбора модели для расчетов.

Для выполнения расчетов МГВМ была адаптирована для использования ее в озерных условиях. Так, в частности, с учетом того, что минерализация воды в озерах Карелии и их притоках различается и ее значения много меньше морской солености, уравнение состояния морской воды было заменено на уравнение состояния слабоминерализованной воды [9]. Кроме того, в мелководных озерах важную роль в тепловом балансе играет теплообмен с дном. Поэтому МГВМ была дополнена специальным модулем для расчета данного параметра [10].

Объектом численного моделирования было выбрано озеро Вендюрское, расположенное в южной Карелии. Подробное описание озера, его батиметрии, особенностей водосбора приведено в работе [11]. Период ледостава продолжается на озере с середины ноября - начала декабря до начала - середины мая. По классификации Льюиса озеро может быть отнесено к классу полимиктических водоемов, поскольку в период открытой воды его водная масса неоднократно перемешивается. Озеро Вендюрское по морфометрическим особенностям и прозрачности, определяющим режим его перемешивания, является типичным представителем класса мелководных полимиктических водоемов, широко распространенных на территории Карелии.

С использованием данных подробной эхолокационной съемки были выполнены соответствующие работы по построению расчетной сетки для Вендюрского озера, параметры которой составили $80 \times 80$ м по горизонтали и 10 горизонтов по вертикали с шагом от 0,5 до 3,5 м. Расчеты выполнялись с шагом по времени 30 с.

В качестве исходной метеорологической информации для расчета «среднеклиматического» состояния ТГД процессов в озере использовались данные реанализа NCEP/ NCAR - совместный проект Национальных центров предсказания окружающей среды (NCEP) и атмосферных исследований (NCAR), СШA [12]. 
Тестовые расчеты были проведены для одного «среднемноголетнего» года со стартовой датой 1 октября. Выбор даты для постановки начальных условий не был случайным. Дело в том, что в октябре термическая структура озера гомогенна по пространству [11]. Это практически единственный месяц в году, когда начальные условия могут быть заданы корректно.

\section{Результаты исследования и их обсуждение}

Анализ результатов численных расчетов показал, что модель адекватно воспроизводит основные особенности термического и динамического режимов озера в годовом цикле при задании среднемноголетнего для района исследований атмосферного форсинга. Даты наступления и окончания ледостава, его продолжительность, годовая амплитуда изменчивости температуры воды на разных глубинах, полученные в результате расчетов, хорошо согласуются с данными натурных исследований [11]. На рис. 1 в качестве примера приведена эволюция температуры воды на разных горизонтах водной толщи в центральной глубоководной части озера в течение одного модельного года (рис. 1, a), а также динамика нарастания и таяния льда (рис. 1, б). Как следует из результатов расчетов, с точки зрения термического режима озеро Вендюрское представляет собой типичный для Карелии и всего северо-запада РФ мелководный водоем со слабо выраженной плотностной стратификацией в период открытой воды. Отчетливо прослеживается весеннее и осеннее полное конвективное перемешивание озера от поверхности до дна, что свойственно подавляющему большинству озер умеренных широт. На этапе летнего нагревания озеро неоднократно полностью перемешивается от поверхности до дна (рис. 1, а). Таким образом, результаты моделирования подтверждают принадлежность Вендюрского озера к классу полимиктических озер.

В озере отчетливо прослеживается так называемый «эффект подледного прогрева» в период ледостава. Данное явление возникает за счет перераспределения в зимний период накопленного донными отложениями тепла между ними и водной массой озера. Воспроизведение моделью подледного прогрева водной массы озера стало возможным благодаря включению в модель специального модуля для расчета теплообмена между водной массой и донными отложениями (см. выше). При этом температура в придонной области повышается до температуры выше значения, соответствующего максимальной плотности $\left(3,98^{\circ} \mathrm{C}\right)$. Данный эффект стал возможен благодаря тому, что в расчетах по МГВМ было использовано уравнение состояния не для пресной, а для слабоминерализованной воды, которое учитывает повышение температуры максимальной плотности за счет минерализации воды.

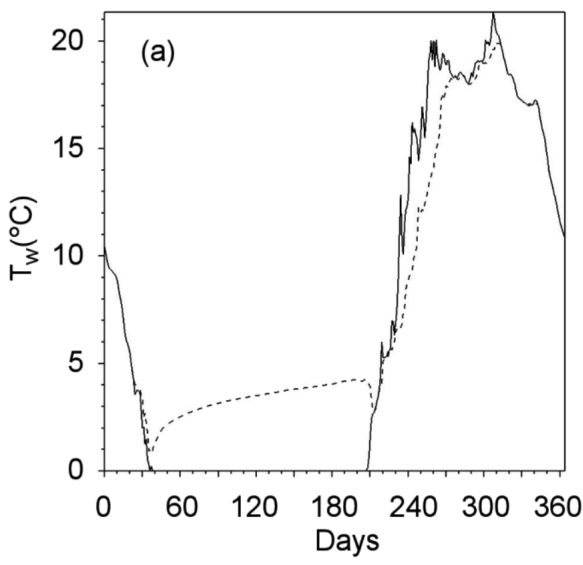

a)

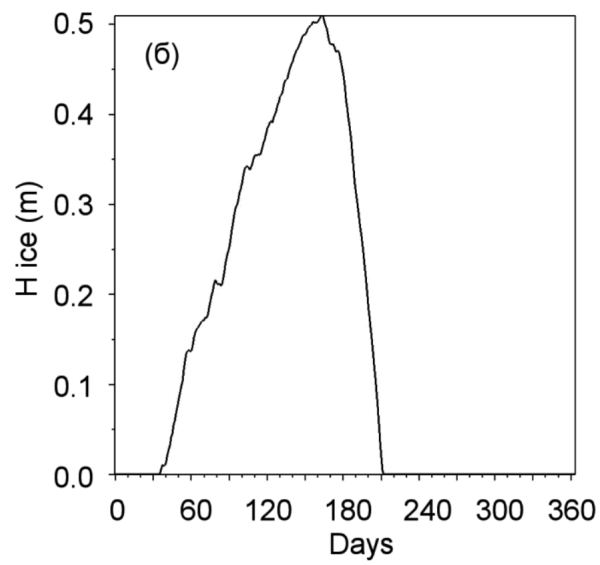

б)

Рис. 1. Температура воды на разных горизонтах водной массы (сплошная линия - поверхность воды, пунктирная - придонный слой) в иентральной глубоководной части оз. Вендюрского в течение года (а) и динамика нарастания и таяния льда (б) при задании среднемноголетнего климатического воздействия. Начало расчета - 1 октября 

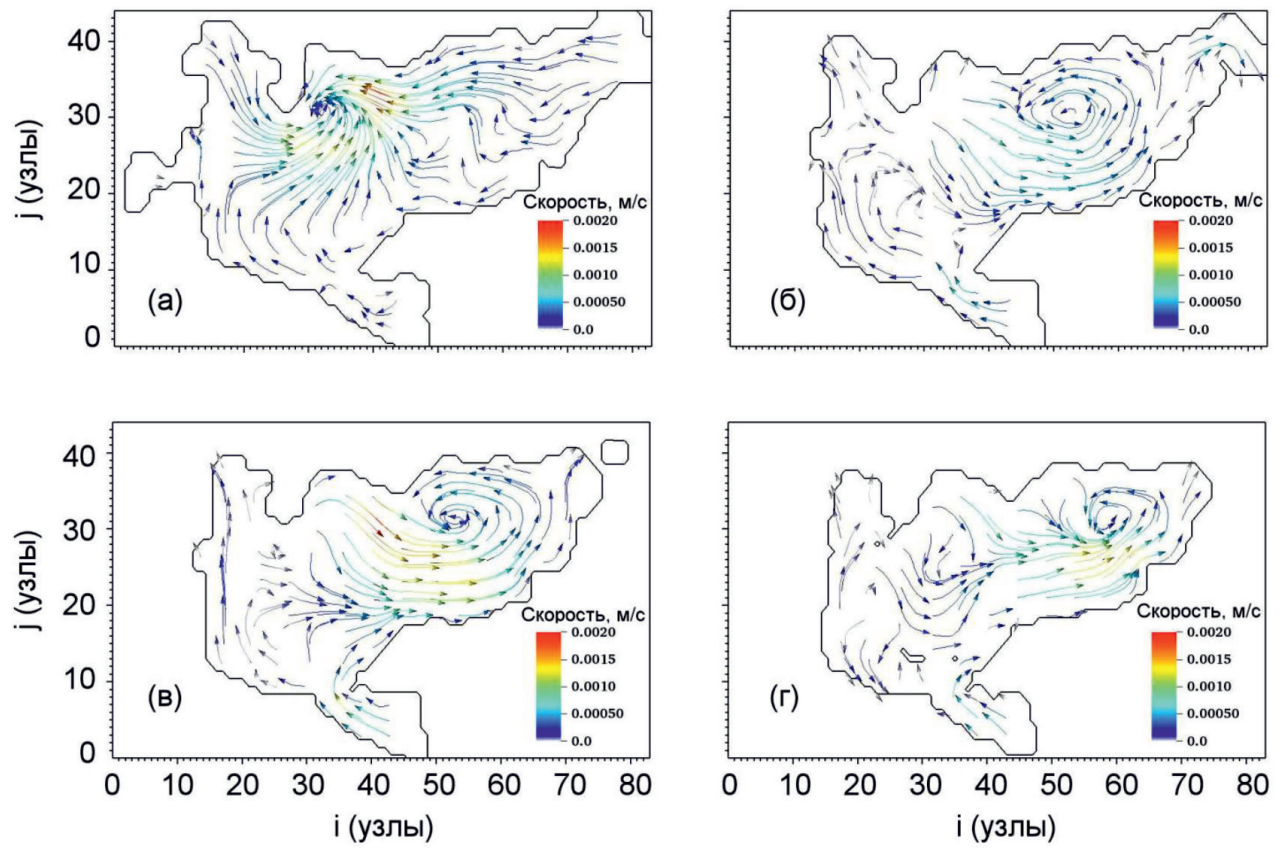

Рис. 2. Поля скоростей течений на глубинах 0,5 м (а), 1,5 м (б), 2,5 м (в) и 5,0 м (2) на 31 января

Также не противоречат данным наблюдений и результаты расчетов образования, нарастания и таяния льда в озере. Так, по данным моделирования первые ледовые явления наступают в озере в начале - середине ноября (рис. 1, б). Нарастание льда происходит до конца марта - середины апреля. Далее наблюдается быстрое таяние ледового покрова с полным его исчезновением в начале - середине мая.

Модельные расчеты течений показали, что вскоре после установления сплошного льда, в озере формируется циклоническая циркуляция, рис. 2, б-г. Эта циркуляция устойчива во времени и существует на протяжении большей части зимы. Скорости течений в поверхностных слоях озера максимальны и достигают 10-15 мм/с в течение первого месяца ледостава, постепенно снижаясь до $0,2-0,5$ мм/с в конце зимы. С увеличением глубины скорости течений уменьшаются, достигая $1-1,5$ мм/с на глубинах порядка 5 м. На рис. 2 приведены поля течений в приповерхностном слое и на глубинах 1,$5 ; 2,5$ и 5 м в середине зимнего сезона (31 января).

Сравнение модельных расчетов скоростей и направлений течений в озере, покрытом льдом, с данными натурных наблюдений [13] показало, что МГВМ удовлетворительно воспроизводит основные особенности динамики водоема в подледный период, а именно, формирование об- щеозерной циркуляции, существующей на протяжении большей части зимнего сезона и постепенное затухание скоростей течений в течение зимы. Появление общеозерной циркуляции в зимний период может быть обусловлено горизонтальной неоднородностью поля плотности, возникающей за счет разной интенсивности осеннего выхолаживания и теплообмена с донными отложениями зимой на прибрежных мелководьях и в центральной глубоководной части озера.

Масштабный анализ [13, 14] показал, что течения в подледный период в оз. Вендюрском носят геострофический характер. Бароклинный радиус деформации Россби ( 200 м) существенно меньше средней ширины озера, а число Россби заметно меньше единицы [14], т.е. эффект вращения Земли может оказывать влияние на формирование крупномасштабной циркуляции. Результаты расчетов на МГВМ показывают формирование циклонического вихря. Натурные измерения, проведенные в разные периоды зимнего сезона, показывают наличие двух циркуляционных ячеек в начале зимнего сезона: циклонической - у северного берега и антициклонической - у южного [13]. Модельное уменьшение скоростей течений к концу зимнего сезона хорошо соответствует наблюдаемому [13] и обусловлено, скорее всего, ослаблением теплообмена водной массы озера с донными отложениями. 


\section{Заключение}

С использованием трехмерной модели гидротермодинамики внутреннего моря (МГВМ), адаптированной для случая пресного озера, получены расчетные поля скоростей течений и температуры воды на разных глубинах мелководного озера Вендюрского. Результаты расчетов показали, что изменения и дополнения, внесенные в МГВМ, позволяют модели адекватно воспроизводить основные ТГД процессы в озере. Принятые в качестве граничных условий в модели потоки тепла и среднемноголетнее атмосферное воздействие позволили получить расчетные данные о полях температуры и скоростей течений, согласующиеся с данными натурных измерений.

В предстоящих численных экспериментах на адаптированной модели планируется получить схемы течений для основных этапов годового цикла - весенне-летнего нагревания, осенне-зимнего охлаждения, зимнего нагревания, а также провести модельные расчеты для разных гидрометеорологических условий, что позволит выявить основные закономерности формирования и изменчивости структуры течений в озере.

Исследование выполнено в рамках государственного задания Института водных проблем Севера КарНЦ РАН, ФИЦ «Карельский научный иентр Российской академии наук».

\section{Список литературы / References}

1. Diaz R.J. Overview of hypoxia around the World. J. Env. Qual. 2001. V. 30. P. 275-281.

2. Kuha J., Arvola L., Hanson P.C., Huotari J., Huttula T., Juntunen J., Järvinen M., Kallio K., Ketola M., Kuoppamäki K., Lepistö A., Lohila A., Paavola R., Vuorenmaa J., Winslow L., Karjalainen J. Response of boreal lakes to episodic weatherinduced events. Inland Waters. 2016. V. 6 (4). P. 523-534. DOI: 10.1080/ IW-6.4.886.

3. Reynolds C.S. The Ecology of Phytoplankton. N.Y.: Cambridge Univ. Press, 2006. 535 p.

4. Rizk W., Kirillin G., Leppäranta M. Basin-scale circulation and heat fluxes in ice-covered lakes. Limnol. Oceanogr. 2014. Vol. 59(2). P. 445-464. DOI:10.4319/lo.2014.59.02.0445.
5. Forrest A.L., Laval B.E., Pieters R., Lim D.S.S. A cyclonic gyre in an ice-covered lake. Limnol. Oceanogr. 2013. Vol. 58 (1). P. 363-375. DOI: 10.4319/1o.2013.58.1.0363.

6. Huttula T., Pulkkanen M., Arkhipov B., Leppäranta M., Solbakov V., Shirasawa K., Salonen K. Modelling circulation in an ice-covered lake. Est. J. Earth Sci. 2010 Vol. 59 (4). P. 298 309. DOI:10.3176/earth.2010.4.06.

7. Ибраев Р.А. Математическое моделирование термогидродинамических процессов в Каспийском море. М.: Геос, 2008. $127 \mathrm{c}$

Ibraev R.A. Mathematical modeling of thermohydrodynamic processes in the Caspian Sea. M.: Geos, 2008. 127 p. (in Russian).

8. Зверев И.С., Ушаков К.В., Шипунова Е.А., Голосов С.Д., Ибраев Р.А. Оценка влияния основных притоков Ладожского озера на формирование водной массы бухты Петрокрепость (исток р. Невы) по результатам математического моделирования: материалы I Международной конференции «Озера Евразии: проблемы и пути решения» (Петрозаводск, 11-15 сентября 2017 г.). 2017. С. 228-233.

Zverev I.|S., Ushakov K.V., Shipunova E.A., Golosov S.D., Ibraev R.A. Effect of the main confluents of Lake Ladoga on the formation of water mass of the Petrokrepost' Bay - the effluent of the Neva river (upon the results of mathematical modelling) // Proc. $1^{\text {st }}$ Intern. Conference «Lakes of Eurasia: Problems and solutions» (Petrozavodsk, 2017). 2017. P. 228-233 (in Russian).

9. Chen C.T., Millero F.J. Precise thermodynamic properties for natural waters covering only limnological range. Limnol. Oceanogr. 1986. Vol. 31. № 3. P. 657-662.

10. Golosov S., Kirillin G. A parameterized model of heat storage by lake sediments // Environmental Modelling and Software. 2010. Vol. 25. P. 793-801.

11. Здоровеннова Г.Э., Гавриленко Г.Г., Здоровеннов Р.Э., Mammarella I., Ojala A., Heiskanen J., Тержевик А.Ю. Эволюция температуры водной толщи бореальных озер на фоне изменений регионального климата // Известия РГО. 2017. Т. 149. Вып. 6. С. 59-74.

Zdorovennova G.E., Gavrilenko G.G., Zdorovennov R.E., Mammarella I., Ojala A., Heiskanen J., Terzhevik A.Y. Evolution of the temperature of the water column of boreal lakes against the background of changes in the regional climate // Proceedings of the Russian Geographical Society, 2017. Vol. 149. Issue 6. P. 59-74 (in Russian).

12. Kalnay et al. The NCEP/NCAR 40-year reanalysis project // Bull. Amer. Meteor. Soc. 1996. Vol. 77. P. 437-470.

13. Malm J., Terzhevik A., Bengtsson L., Boyarinov P., Glinsky A., Palshin N., Petrov M. A field study on currents in a shallow ice-covered lake. Limnol. Oceanogr. 1998. Vol. 43. P. 1669-1679.

14. Пальшин Н.И., Здоровеннова Г.Э., Богданов С.Р., Волков С.Ю., Гавриленко Г.Г., Ефремова Т.В., Здоровеннов Р.Э., Тержевик А.Ю. Геострофические течения в малом озере подо льдом // Успехи современного естествознания. 2017. № 11. C. 89-94.

Palshin N.I., Zdorovennova G.E., Bogdanov S.R., Volkov S.Yu., Gavrilenko G.G., Efremova T.V., Zdorovennov R.E., Terzhevik A.Yu. Geostrophic currents in the small ice-covered lake // Advances in current natural sciences. 2017. № 11. P. 89-94 (in Russian). 